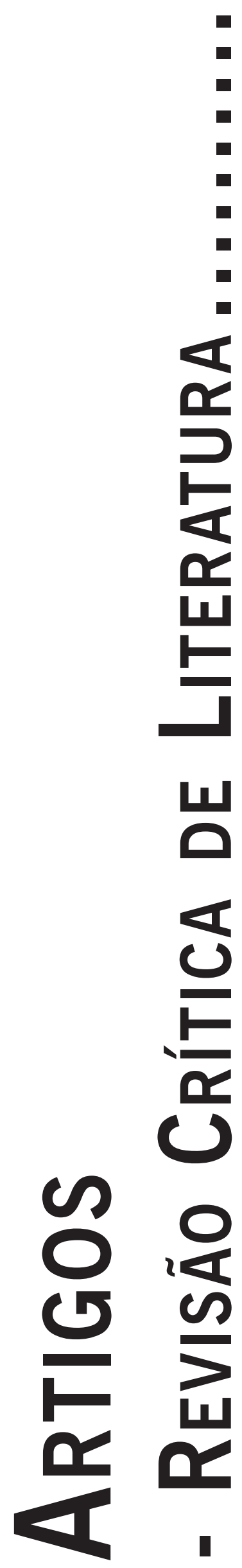




\title{
DASEINSANALYSE E PSICOTERAPIA NO BRASIL: UMA REVISÃO INTEGRATIVA DA LITERATURA
}

\author{
Daseinsanalysis and Psychotherapy in Brazil: An Integrative Literature Review
}

Daseinsanalyse y Psicoterapia en Brasil: Una Revisión Integradora de la Literatura

Breno Augusto da Costa

\begin{abstract}
Resumo: A daseinsanalyse é uma escola de psicoterapia desenvolvida por Medard Boss fundamentada no pensamento heideggeriano. Considerando a demanda da caracterização da produção em psicoterapia existencial na Latino-América esse estudo foi desenvolvido com o objetivo de elaborar um panorama geral da produção brasileira em daseinsanalyse. Trata-se de uma revisão integrativa da literatura a partir da "Revista Daseinsanalyse". Foram destacadas as influências teóricas, os objetivos da psicoterapia e a postura do terapeuta. A produção brasileira em daseinsanalyse encontra no pensamento de Heidegger sua influencia principal, mas também fundamenta-se em outros existencialistas. Os objetivos da psicoterapia apontam ao desvelamento de sentidos, uma nova compreensão da afinação do paciente e promoção de liberdade existencial. As posturas do terapeuta envolvem acolhimento, aproximação e aceitação em relação ao paciente. O terapeuta deve possuir uma perspectiva clínica e clarear as experiências do paciente. A interpretação integradora indica uma dispersão de objetivos e posturas do terapeuta que convergem na direção do cuidado do ser, sendo a daseinsanalyse uma prática de terapia no sentido primordial do termo. $\mathrm{O}$ artigo aponta como nova perspectiva a possibilidade do pensamento daseinsanalítico fundamentar a prática da redução de danos.
\end{abstract}

Palavras-chave: Daseinsanalyse; Psicoterapia; Boss; Heidegger; Redução de danos.

Abstract: Daseinsanalysis is a psychotherapeutic school developed by Medard Boss grounded in the heideggerian thought. Considering the need for characterizing the Latin-American production in existential psychotherapy this study was developed aiming to elaborate a general framework of the Brazilian production in daseinsanalysis. This is an integrative literature review from the Brazilian journal "Revista Daseinsanalyse". The theoretical influences, psychotherapy goals and the therapist's attitudes were highlighted. The Brazilian daseinsanalysis literature finds in the heideggerian thought its major influence but also is founded in other existentialists. The psychotherapy goals points out to the unveiling of meanings, a new comprehension of the patient attunement and the promotion of the patient's existential freedom. The therapist posture includes embracement, proximity and acceptance towards the patient. The therapist must possess a clinical perspective and clarify the patient's experiences. The integrative interpretation shows a dispersion of goals and therapists attitudes converging towards the care of the being, as daseinsanalysis is a therapeutic practice in the primordial meaning of the term. The paper shows as new perspective the possibility of the deseinsanalitic thought to be a foundation to harm reduction.

Keywords: Daseinsanalysis; Psychotherapy; Boss; Heidegger; Harm reduction.

Resumen: El Daseinsanalyse es una escuela de psicoterapia desarrollada por Medard Boss fundada en el pensamiento de Heidegger. Teniendo en cuenta la demanda de la caracterización de la producción en psicoterapia existencial en América Latina este estudio fue desarrollado con el objetivo de elaborar una visión general de la producción brasileña en Daseinsanalyse. Se trata de una revisión integradora de la literatura de la "Revista Daseinsanalyse". Fueran destacadas las influencias teóricas, los objetivos de la psicoterapia y la postura del terapeuta. La producción brasileña en Daseinsanalyse encontró en pensamiento de Heidegger sus principales influencias, pero también se basa en otros existencialistas. Los objetivos de la psicoterapia apuntan a la develación de los sentidos, una nueva comprensión de los estados de ánimo del paciente y la promoción de la libertad existencial. La postura del terapeuta implica acogida, aproximación y la aceptación del paciente. El terapeuta debe tener un punto de vista clínico y aclarar las experiencias del paciente. La interpretación integradora señaló una dispersión de objetivos y las intenciones del terapeuta pero que convergen hacia el cuidado del ser, siendo Daseinsanalyse una práctica de la terapia en el sentido primario. El artículo señala cómo nueva perspectiva la posibilidad del pensamiento daseinsanalítico fundamentar la práctica de la reducción de daños. Palabras-clave: Daseinsanalyse; Psicoterapia; Boss; Heidegger; Reducción de daños.

\section{Introdução}

A Daseinsanalyse enquanto prática psicoterapêutica tem suas origens na apropriação pioneira realizada por Ludwig Binswanger do pensamento de Martin Heidegger, especialmente as noções expressas na obra "Ser e Tempo" (1927/2012). A proposta de Binswanger era encarar a clínica, a patologia e a realidade existencial do paciente a partir de uma perspectiva fenomenológica, destacando-se do pensamento científico hegemônico de então (Boss \& Condrau, 1976/1997; Holanda, 2014). No entanto, partir de uma série de críticas realizadas pelo próprio Heidegger em torno da compreensão errônea de determinados pontos de sua filosofia, Binswanger afastou-se do pensamento heideggeriano, cabendo ao psiquiatra suíço Medard Boss a tarefa de continuar empreendendo o desenvolvimento da daseinsanalyse, recebendo o suporte intelectual de direto Heidegger (Boss \& Condrau, 1976/1997, Heidegger, 1987/2001). 
A rigor a daseinsanalyse deve ser considerada uma terapia e não psico-terapia, pois prescinde de construtos psíquicos conforme discutem diferentes pensadores. Apesar disso advertimos o leitor que utilizamos o termo psicoterapia e psicoterapeuta neste trabalho apenas por convenção acadêmica.

O termo daseinsanalyse é composto por duas palavras compreendidas de um modo bastante específico por Heidegger. Levando-se em conta sua preocupação filosófica fundamental, o problema do ser, o termo dasein é usado como o substantivo designador do ente humano (Heidegger, 1927/2012, p. 1185). Por outro lado, análise em Heidegger tem uma conotação diferente do processo cartesiano de fragmentação de um objeto para a realização do estudo individualizado de suas partes e, posteriormente, a apreensão do todo. Heidegger (1987/2001) defende análise como um processo de libertar-se das algemas ou o tecer e destecer de uma trama. Dessa forma, nesse trabalho, escolheu-se redigir daseinsanalyse com "y" para expressar o sentido da análise a partir das reflexões heideggerianas.

Em "Ser e Tempo" (1927/2012) Heidegger utilizou o termo daseinsanalyse, restrito inicialmente ao âmbito da ontologia; o termo foi usado com o intuito de designar a explicitação filosófica dos existenciais, ou seja, das características ontológicas constituintes do existir humano. A partir da apropriação pioneira de Binswanger e da ulterior elaboração de Boss foi utilizado o termo daseinsanalyse clínica, ou simplesmente daseinsanalyse, para designar essa prática psicoterapêutica em discussão (Cardinalli, 2012). A insatisfação de Medard Boss com as bases do pensamento psicanalítico e psiquiátrico em voga na sua época é considerada o móvel para a busca de uma fundamentação alternativa no pensamento heideggeriano (Boss \& Condrau, 1976/1997; Evangelista, 2013; Giovanetti, 2012). No entanto a daseinsanalyse pode ser considerada um desdobramento da psicanálise, mesmo modificando os pontos fundamentais da prática psicanalítica, tal como a associação livre e a interpretação dos sonhos. A compreensão de homem também é extremamente diferente, uma vez que a metapsicologia freudiana é abandonada em prol de uma compreensão baseada na ontologia heideggeriana, cujos existenciais ocupam lugar de destaque. (Cardinalli, 2012; Boss, 1963). Os existenciais são possíveis modos de ser, e não categorias ou atributos; os existenciais possuem relevante papel na prática clínica daseinsanalítica e são: a temporalidade, a espacialidade, o ser-com-o-outro, a afinação, a compreensão, o cuidado, a queda e o ser-mortal (Cardinalli, 2012).

Medard Boss (1963) pontua como atitude fundamental do psicoterapeuta a "descrição e investigação de todos os modos de comportamento humano imediatamente observáveis e de suas afinações subjacentes igualmente perceptíveis" (p. 233), evidenciando o trabalho com o conteúdo manifestado no encontro terapêutico a partir do próprio conteúdo, sem uma lente teórica por trás desse olhar clínico, assim instaura-se uma genuína relação de abertura do psicoterapeuta ao paciente e seu modo de ser. Boss assinala também a atitude de aceitação em torno de toda manifestação do paciente, uma vez que a "compreensão daseinsanalítica de homem impregna o analista com um respeito profundo por tudo por ele encontrado" (p. 235). Dessa forma o psicoterapeuta deve também aceitar os diversos modos de ser do paciente.

Evangelista (2013) destaca a o interesse do daseinsanalista em "conhecer os incidentes biográficos motivadores que levaram o ser-no-mundo a restringir suas possibilidades" (p. 155), como resultado da recusa da daseinsanalyse em assumir o modelo causal. Pontua a situação do dasein enquanto lançado em possibilidades de ser e aborda a questão da culpa e limitação da existência. O encontro entre psicoterapeuta e paciente, segundo o autor, é um processo de cuidado de solicitude libertadora visando a libertação da existência do paciente.

A entrada da daseinsanalyse no contexto brasileiro ocorreu na década de 70 a partir dos contatos entre Solon Spanoudis e Medard Boss. A fundação da Associação Brasileira de Análise e Terapia Existencial - Daseinsanalyse (ABATED) em 1973 foi fundamental para o desenvolvimento da daseinsanalyse no Brasil, pois servia como referência em daseinsanalyse, além de congregar e formar novos terapeutas nessa perspectiva, publicar a "Revista Daseinsanalyse" e propor discussões entre o pensamento heideggeriano e suas interlocuções com outras disciplinas. Atualmente tal instituição é denominada Associação Brasileira de Daseinsanalyse (ABD), tendo mantido os objetivos iniciais (Associação Brasileira de Daseinsanalyse, 2015; Evangelista, 2013). O estudo de Correia, Correia, Cooper e Berdondini (2014), reconhece a ABD como a única instituição pertecente exclusivamente à perspectiva daseinsanalítica na Latino-América.

Conforme apontado por Correia et al. (2014) a prática de psicoterapia existencial na Latino-América é extremamente ativa, sendo este um dos centros mais dinâmicos no panorâma mundial. No entanto, com base na pouca referência que ela tem na literatura europeia e norte-americana, os autores apontam a necessidade de maiores estudos elaborando o perfil dessa produção, um vez que não são conhecidos estudos elaborando suas principais características.

Considerando a demanda elaborada por Correia et al (2014) e a escassez de revisões sistemáticas acerca da produção brasileira em daseinsanalyse, o objetivo desse estudo foi elaborar um panorama geral da produção brasileira em daseinsanalyse, considerando as influências teóricas, os objetivos da psicoterapia e a postura do terapeuta segundo a literatura estudada.

\section{Método}

Foi realizada uma revisão integrativa da literatura. Tal método revisa, critica e sintetiza a literatura disponível permitindo um novo panorama integrado dos saberes produzidos (Torraco, 2005). O autor afirma que a revisão integrativa é endereçada a dois tipos de tópicos: os maduros e os emergentes. No primeiro caso ela deve ser desenvolvida criticamente, empreendendo uma reconceituação da temática e assim oferecer bases de conhecimento mais 
diversificadas sobre aquele tema. Já no caso dos tópicos emergentes a revisão integrativa permite a conceituação holística e uma síntese da literatura produzida. Optou-se pelo uso dessa metodologia com o intuito de fornecer uma visão geral da produção científica nacional em daseinsanalyse e elaborar uma estruturação da produção desse tópico através da abordagem fundamentada na revisão integrativa.

Concebe-se a produção nacional em daseinsanalyse como madura em certos aspectos, porém marcada paradoxalmente pela falta de síntese e estruturação sistemática, em outros. Dessa forma, ao invés de classificar o tema de estudo como maduro ou emergente, é empreendida a tarefa essencial da revisão integrativa, que de acordo com Torraco (2005) é oferecer um quadro sintetizado da literatura em uma estruturação conceitual que oferece novas perspectivas sobre o tópico.

Para a escolha dos artigos abordados foram realizados os seguintes procedimentos: tomando como base de dados a "Revista Daseinsanalyse" foi realizada uma busca de textos a partir de três etapas: uma seleção de textos a partir das seguintes palavras-chave: "psicoterapia” ou "terapia” ou "daseinsanalyse" e em seguida a aplicação de critérios de inclusão e exclusão. Finalmente foram recuperados apenas os textos relacionados ao objetivo da pesquisa. Justifica-se a escolha desse periódico pelo significado de periódico-referência na difusão de conhecimento e saberes no campo da daseinsanalyse no Brasil, trazendo contribuições originais e relatos dos formadores e terapeutas atuantes nessa abordagem.

Os critérios de inclusão utilizados foram: textos relacionados ao tema; textos cujo corpo aborda a questão da psicoterapia daseinsanalítica. Já os critérios de exclusão foram: textos escritos por autores estrangeiros; textos não relacionados ao tema; textos que abordam a psicoterapia tangencialmente. Não houve restrição temporal na busca pelos textos, além disso, o delineamento metodológico dos textos não impediu sua inclusão. Tais medidas foram tomadas com o intuito de abranger o maior número de textos possível, demonstrando um quadro abrangente da produção da "Revista Daseinsanalyse". No caso dos volumes que não contavam com palavras-chave foi realizada uma leitura flutuante dos artigos visando selecionar aqueles que se encaixavam no objetivo da pesquisa.

Após a realização desse procedimento de coleta de textos, foi realizada uma leitura atenciosa e a identificação dos seguintes temas: (a) Pressupostos teóricos e influências filosóficas; (b) Objetivos da psicoterapia; e (c) Posturas do psicoterapeuta. Em seguida foi realizada a leitura crítica e a interpretação sintética dos textos, visando apontar novos contextos de atuação a partir do referencial daseinsanalítico.

\section{Resultados}

Os textos coletados a partir da pesquisa na "Revista Daseinsanalyse" foram um total de 16. A Tabela 1 apresenta a quantidade de textos encontrados após a seleção com as palavras-chave, selecionados de acordo com o resumo e recuperados, após uma leitura atenciosa.

Tabela 1: Quantidade de textos encontrados após a seleção

\begin{tabular}{|ll|}
\hline & Revista Daseinsanalyse \\
\hline Encontrados & 27 \\
\hline Selecionados & 22 \\
\hline Recuperados & 16 \\
\hline
\end{tabular}

Observa-se que dentre os artigos selecionados seis não foram recuperados. Verificou-se que tais trabalhos abordaram temas relevantes para a prática psicoterapêutica, porém só tangenciavam uma discussão sobre a psicoterapia. Os textos recuperados foram dispostos na Tabela 2, onde são apresentados seus títulos, autores, ano da publicação e tipo de estudo:

Tabela 2: Títulos, autores, ano da publicação e tipo de estudo

\begin{tabular}{|c|c|c|c|c|}
\hline$n^{0}$ & Título do Texto & Autores & Ano & Tipo de estudo \\
\hline 1 & Psicoterapia: uma aproximação Daseinsanalítica & David Cytrynowicz & 1978 & Teórico \\
\hline 2 & Psicoterapia e Verdade & João Pompéia & 1978 & Teórico \\
\hline 3 & Relação Analista-Analisando: uma abordagem daseinsanalítica & Maria Cytrynowicz & 1997 & Teórico (Palestra) \\
\hline 4 & Daseinsanalyse e Psicoterapia & Ida Cardinalli & 2000 & Teórico \\
\hline 5 & Uma Caracterização da Psicoterapia & João Pompéia & 2000 & Teórico (Palestra) \\
\hline 6 & A História de Julia & Fernanda Vianna & 2001 & Estudo de Caso (Palestra) \\
\hline 7 & Relato de um Processo Terapêutico de uma Criança Institucionalizada & Maurício Castejón Hermann & 2001 & Estudo de Caso (Palestra) \\
\hline 8 & Uma História de Abandono & Adriana Puzzilli & 2001 & Estudo de Caso (Palestra) \\
\hline 9 & Descoberta de um Encontro Através do Brincar & Sérgio Kuroda & 2001 & Estudo de Caso (Palestra) \\
\hline 10 & Comentários & Maria Cytrynowicz & 2001 & Teórico (Palestra) \\
\hline 11 & Psicose e Psicoterapia & João Pompéia & 2002 & Teórico (Palestra) \\
\hline 12 & A Dependência de Drogas e a Fenomenologia Existencial & Fabiano Sipahi \& Fernanda Vianna & 2002 & Teórico \\
\hline 13 & A História de Camila & Fabiana Saffi & 2002 & Estudo de Caso \\
\hline 14 & Aspectos Emocionais na Terapia Daseinsanalítica & João Pompéia & 2004 & Teórico (Palestra) \\
\hline 15 & A Contribuição das Noções de Ser-no-Mundo e Temporalidade para a Psicoterapia Daseinsanalítica & Ida Cardinalli & 2005 & Teórico (Simpósio) \\
\hline 16 & Daseinsanalyse e Liberdade & Danielle de Freitas & 2011 & Teórico \\
\hline
\end{tabular}


Observa-se uma grande presença de textos oriundos de palestras ou apresentados também em seminários. Do total de 16 textos, 10 deles foram apresentados como palestras ou em eventos científicos, tal como informado em notas de rodapé nos textos. Por outro lado os artigos podem ser divididos em dois grupos de acordo com o tipo de estudo: estudos teóricos e estudos de caso. Cinco dos estudos recuperados eram estudo de caso, concentrados especialmente na revista de número 10 (2001). A daseinsanalyse enquanto prática psicoterapêutica recebe grandes contribuições de estudos de caso, pois estes trazem as experiências dos psicoterapeutas atuando. Já os estudos teóricos são componentes enriquecedores da compreensão do existir humano e dos fenômenos que são tematizados e estudados. Na maioria dos estudos teóricos foram encontrados diversos fragmentos de casos clínicos.

Em relação aos objetivos, alguns textos ao invés de apresentar objetivos explícitos, propunham questões ou problemáticas norteadoras das reflexões. Percebeu-se uma grande dispersão dos objetivos embora a palavra psicoterapia estivesse presente na maior parte.

\section{Influências teóricas}

Dentre as influências, Heidegger ocupa lugar central. O papel fundamentador de Heidegger é enfatizado a partir da obra Ser e Tempo (1927/2012) e sua proposta ontológica; David Cytrynowicz (1978/1997) cita a ontologia fundamental de Martin Heidegger, expressa na obra Ser e Tempo (1927/2012), como o marco de referência da concepção de homem da daseinsanalyse. Ato contínuo à assimilação do pensamento de Heidegger, a daseinsanalyse aborda a natureza humana como sendo essencialmente abertura, um dos existenciais explicitados por Heidegger. David Cytrynowicz (1978/1997) destaca que esse existencial se refere à condição básica do existir humano enquanto poder-ser. Sipahi e Vianna (2002) afirmam que "o ser humano encontra-se sempre, de um modo mais aberto ou mais restrito, em afinação com o que lhe vem ao encontro" (p. 88). O dasein sempre encontra-se em um estado de humor, assim o encontrar-se (Befindlichkeit) é cotidianamente tratado como estado de humor ou disposição afetiva (Heidegger, 1927/2012). Segundo Gendlin (1978) o encontrar-se denota como nos sentimos nas situações cotidianas, referindo tanto a algo interior quanto exterior, uma vez que o homem vive enquanto ser-no-mundo, mas vivendo com o mundo. Freitas (2011) esclarece que as tonalidades afetivas (Stimmung) “colorem não apenas o momento presente, mas também ressignificam os fatos da história passada e os projetos de futuro” (p. 69). Pompéia (2004) destaca a imbricação entre a afinação e a clareira do ser (Lichtung) afirmando que a afinação é uma luz que vigora na clareira, iluminando todos os entes e acontecimentos que se manifestam nessa clareira. Assim a compreensão que o Dasein tem de si próprio e do mundo é sempre afinada devido a essa condição do encontrar-se. Maria Cytrynowicz (2000) cita Heidegger para discutir o papel do jogo na existência humana e assim fundamenta o brincar como um estar afinado. O brincar, segundo a autora, é o melhor caminho para a atuação do terapeuta com crianças.

Citando Heidegger (1927/2012) "a essência do Dasein reside em sua existência” (§9), os autores Sipahi e Vianna (2002) realizam a leitura de que o homem não é constituído de antemão, mas sim se constitui se construindo, existindo e caminhando em direção ao futuro. Segundo os autores, o homem existe lançado em um mundo e deve cuidar de sua existência, atentando para as possibilidades em seu horizonte. Dentre as possibilidades que o homem possui, a morte apresenta-se como possibilidade última, impondo um limite ao seu ser. Cerbone (2014) afirma que a morte não pode ser superada, sendo assim é a possibilidade mais própria do homem, uma vez que ele não pode renunciá-la ou passa-la adiante. O autor também discute a relação ser-para-a-morte e autenticidade.

Maria Cytrynowicz (1997) cita a concepção heideggeriana de ser-no-mundo, caracterizando o ser humano fundamentalmente como um movimento junto a pessoas ou coisas em um lugar qualquer, dando à existência um caráter de coexistir. Cardinalli (2000) endossa o uso da noção ser-no-mundo na situação terapêutica apontando que o modo de existir no mundo do paciente deve ser abordado. Em outro trabalho (2005) Cardinalli chega a afirmar que "o foco da situação terapêutica é a maneira como determinada pessoa está se relacionando consigo mesma, com os outros e com tudo o que se apresenta em seu mundo" (p. 58). Nesse sentido é importante compreender que o ser do homem é um ser-no-mundo, esse "no" não deve ser compreendido como dentro de determinada cota de espaço no mundo, mas sim ser com o mundo (Boss, 1963, p. 33-34).

A realização dos Seminários de Zollikon é destacada como espaço articulador entre o pensamento de Heidegger e a psicoterapia. Cardinalli (2000) referencia os Seminários de Zollikon em seu trabalho para discutir a relação terapêutica com bases heideggerianas. Dessa forma os fenômenos que surgem na relação do terapeuta e paciente devem ser discutidos a partir do paciente concreto. Prado (2001) desenvolve um estudo que vista descrever o surgimento da obra "Seminários de Zollikon" (1987/2001) assim como descrever os próprios seminários a partir de trechos da obra.

Ainda em torno da influência heideggeriana, Cardinalli (2000) afirma que as concepções do filósofo acerca da linguagem "permitem situar o entendimento daseinsanalítico do falar no contexto terapêutico" (p. 15). Dessa forma cita algumas colocações contidas no §12 de Ser e Tempo (1927/2012) para estabelecer as concepções heideggerianas do falar e discuti-las na psicoterapia.

Pompéia (2000) também fundamenta a daseinsanalyse em bases heideggerianas quando afirma que a psicoterapia acontece via poiesis, ou seja, via um trazer à luz aquilo que se apresenta. $\mathrm{O}$ autor, ao propor o caminho da 
psicoterapia via linguagem poética, coloca a compreensão em evidência, uma vez que nessa via de linguagem o interlocutor, ou terapeuta, é tocado pela fala do paciente de uma forma distinta da explicação racional. Em seguida para expressar aquilo que se manifesta na fala do paciente via linguagem poética o autor introduz a noção de aletheia como explicitada por Heidegger, ou seja, aquilo que se mostra desvelado. Em outro trabalho Pompéia (1978/1997) aponta que o paciente longe de ser uma “colcha de retalhos, de eventos e problemas independentes, é uma totalidade [...] móvel e palpitante, própria, peculiar, nova a cada momento" (p. 75), dessa forma cita a concepção heideggeriana de aletheia como o subsídio para a compreensão da verdade em psicoterapia, ou seja, da totalidade que se apresenta no contexto terapêutico. O conceito aletheia também foi tematizado por Pompéia (2004) e Freitas (2011), bem como outros autores.

Boss (1981) é citado por Pompéia na tematização da questão da angústia e culpa na psicoterapia. A concepção de Boss é a de que a angústia é a expressão da assimilação da possibilidade de não mais poder ser, ou seja, da morte. A angústia é vista basicamente como medo da morte que se apresenta ao Dasein como possibilidade, seja através de situações factuais ou do desamparo provocado pela falta de amor (p. 26-28). Mas também Pompéia traz uma tese original acerca da motivação da angústia afirmando que:

a angústia existencial diz respeito ao desamparo tremendo que o Dasein vive quando se apropria de si mesmo, isto é, quando se percebe, com maior ou menor clareza, aberto e lançado na indeterminação dos fatos do futuro, o que é profundamente aflitivo e assustador. E não é só diante da indeterminação do futuro que ele vive. O significado dos fatos do passado também é indeterminado, pois o significado do vivido pode mudar radicalmente à medida que as coisas vão acontecendo. E isso também é aflitivo e assustador. Estar lançado nessa indeterminação é angustiante. $(2004$, p. 13$)$

Assim, frente à sua liberdade, iluminado por uma tonalidade afetiva, o homem enfrenta a angústia existencial como a expressão genuína do seu poder-ser. Aberto, seu futuro se apresenta cheio de possibilidades as quais inexoravelmente o homem deve escolher; algumas em detrimento de outras. Toda escolha pressupõe a exclusão de uma série de outras, e é a escolher que o homem é fadado.

Maria Cytrynowicz (1997) afirma que a daseinsanalyse possui uma base fenomenológica, no entanto a autora não dá mais explicações acerca dessa posição. Cardinalli (2005) aponta que a daseinsanalyse baseia-se na fenomenologia ou método fenomenológico tal como explicitados por Heidegger (1987/2001). No §7 de Ser e Tempo (1927/2012) Heidegger afirma que o modo-de-tratamento à pergunta do ser é o fenomenológico, uma vez que segundo ele "a ontologia só é possível como fenomenologia" (p. 123). Em seguida o filósofo aponta a fenomenologia do Dasein como uma hermenêutica, ou seja, uma tarefa de interpretação. Heidegger destaca o papel de Husserl e seu pensamento como fundamento para a elaboração de suas investigações, porém chega a pontuar uma concepção de redução fenomenológica divergente de Husserl já no §5 de "Os Problemas Fundamentais da Fenomenologia" (1975/2012). Cerbone (2014) aborda a distinção entre fenomenologia como concebida por Husserl e por Heidegger.

Em outro trabalho Cardinalli (2000) afirma que a daseinsanalyse percorre um caminho fenomenológico e justifica citando a concepção de fenômeno de Medard Boss (1984/1997), ou seja, fenômeno enquanto um mostrar-se, tomado a partir da forma como se mostra para o próprio paciente. Boss e Condrau (1976/1997) afirmam que a abordagem daseinsanalítica é fenomenológica uma vez que visa, em sua essência, ver aquilo que se mostra a partir de si mesmo. Isso implica ver o fenômeno a partir dele próprio e não a partir de teorias explicativas ou uma metapsicologia de qualquer tipo.

Outro autor que cita a fenomenologia é Pompéia (2002, 2004). O autor se fundamenta na pesquisa fenomenológica para justificar a posição do terapeuta de aceitar a experiência de realidade do paciente, uma vez que o terapeuta não dispõe de recursos para demonstrar a realidade ou não dessa experiência. Ele cita a suspensão de julgamento enquanto uma redução fenomenológica para evitar a interferência das crenças e descrenças do pesquisador nos resultados da pesquisa. Concebemos que a daseinsanalyse, de certa forma, pode ser interpretada como uma escola de psicoterapia fenomenológico existencial. Argumentamos que o empreendimento da daseinsanalyse é similar ao da fenomenologia no sentido de ser reativo a um modelo naturalista vigente. Pretendemos abordar essa temática em outro trabalho.

Pompéia (2000) cita outro pensador existencialista, Sartre, para abordar a questão da liberdade, especialmente o incômodo motivado por ela e que é sentido pelo paciente na condução de sua existência. $\mathrm{O}$ autor cita a interpretação de liberdade como um livrar-se de algo, assim quando o paciente exerce essa liberdade, enfrenta o abandono e desligamento. Além dessa interpretação cita liberdade como relacionada a um sentido, uma forma de romper com um modo de ser anterior e assumir a dedicação a um novo rumo. Em certos pontos o pensamento de Sartre é divergente do pensamento de Heidegger (Holanda, 2014, p. 146-148; Mondin, 2014, p. 227-228), porém há diversos paralelos possíveis entre esses dois pensadores da fenomenologia existencial.

Freitas (2011) tematiza o conceito liberdade e sua posição fundamental na prática da psicoterapia tal como caracterizada por Pompéia (2000). A autora cita as concepções de Berlin e Tugendhat de liberdade e em seguida tematiza a concepção heideggeriana, afirmando que esta abrange as outras duas, mas também aponta para o fundamento essencial da liberdade: ser um evento humano. 
Diferente dos outros seres, influenciados por relações causais, o homem é um poder-ser, assim a liberdade dos homens é a abertura para as suas possibilidades existenciais. A autora afirma que "Dasein é jogado no mundo com a necessidade de cuidar de sua liberdade. Não nos é oferecida a escolha: esta tarefa nos é impelida" (p. 63). Freitas também citou Hanna Arendt para discutir a questão liberdade contradita pelo determinismo. Maria Cytrynowicz (2001) cita também Hanna Arendt para comentar uma série de estudos de caso de psicoterapia com crianças institucionalizadas. A pensadora alemã, discípula de Heidegger, traz reflexões em torno da significação do mundo público e do mundo privado, usadas por Maria Cytrynowicz como fundamentação na discussão do contexto de uma criança institucionalizada.

É importante salientar a diferença entre uma influência teórica central na daseinsanalyse, Heidegger, e outros autores usados na compreensão de diversos aspectos da existência e experiência humana.

\section{Objetivos da psicoterapia}

David Cytrynowicz (1978/1997) afirma que "a psicoterapia deve apontar para a liberdade do homem” (p. 69), desvelando os sentidos que fundamentam a compreensão da sua própria existência. Freitas (2011) traz uma definição similar, concebendo a liberdade como "o horizonte mais próprio do percurso da psicoterapia” (p. 56). Em seguida a autora cita Boss, que estabelece que o objetivo da psicoterapia é "favorecer a liberdade existencial dos pacientes" (p. 57). Sipahi e Vianna (2002) também colocam a liberdade como o ponto orientador da psicoterapia, concebendo liberdade a partir de uma articulação com a abertura. Os autores apresentam, portanto, um desdobramento da concepção de homem enquanto um ser existente que se constrói a partir de suas escolhas.

Pompéia (1978/1997) inicia o texto citando Spanoudis (1976/1997): "Conseguir a autenticidade esclarecida da própria existência humana, eis o que a se tenta no encontro psicoterápico" (p. 53). Considerando o referencial heideggeriano empregado na daseinsanalyse, autenticidade vincula-se à condição de finitude do homem, mas também vincula-se à relação do indivíduo com a-gente (das Man) (Cerbone, 2014). Maria Cytrynowicz (1997) afirma que "são justamente procura e disponibilidade para a acompanhar a destinação e significação da terapia" (p. 33-34). Procura quer dizer a busca por uma saída de qualquer restrição de possibilidades experienciada pelo paciente. Logo depois a autora sustenta a existência de diversos modos de manifestação dessa restrição: “(...) vivências de falta, como a insegurança, a desconfiança, o temor e a inferioridade, até as de excesso e avidez, como as da pessoa ansiosa que quer tudo e rapidamente, ou daquela que sempre desafia e que em tudo percebe uma ocasião para competir e se pôr à prova” (p. 36).
Os conteúdos e o contexto de manifestação dessas restrições são diferentes, porém a autora afirma que em todos os casos é presente a impossibilidade de realizar um viver mais pessoal. Já a disponibilidade para acompanhar é a atitude do terapeuta que favorece a procura do paciente. Maria Cytrynowicz (1997) pontua também que a condição básica da terapia é a aproximação entre o terapeuta e paciente, gerando um espaço de intimidade e maior proximidade consigo mesmo, ou seja, o paciente deve acercar-se de "seus anseios, as suas dúvidas, os seus temores, certezas e incertezas" (p. 37). Tal aproximação empreendida pelo paciente ocorre graças ao compartilhamento entre terapeuta e paciente (Freitas, 2011).

Pompéia (2000) concebe que na terapia o paciente deve reencontrar a expressão de seu modo de sentir, ou seja, re-cordar, especialmente as coisas que já foram caras. O autor apresenta a origem do termo recordar, apontando o radical cor-cordis, que significa coração e o prefixo re, indicando uma repetição. Assim re-cordar é trazer novamente ao coração. Em uma articulação com o pensamento heideggeriano vale por em consideração o encontrar-se, especialmente sua manifestação ôntica através dos estados de ânimo; Freitas (2011) coloca como fundamental na prática psicoterápica a escuta dos estados de ânimo.

Saffi (2002) afirma que "a função da psicoterapia não é retirar a pedra que atrapalha o caminho, mas sim, fornecer subsídios para o que o cliente possa transpô-la ou desviar-se dela" (p. 104). Assim as metas da psicoterapia, na perspectiva do terapeuta, não devem ser eliminar os sintomas, tal como já apontado por Pompéia (2002) e David Cytrynowicz (1978/1997), mas sim o cuidado do próprio paciente. Ainda segundo Saffi (2002), considerando que "os fatos não mudam e o que muda é o sentido dados a eles, o trabalho da psicoterapia é tentar mudar o seu sentido" (p. 104). Tal concepção, que a autora traz fundamentando-se em um curso ministrado por Pompéia, permite ao psicoterapeuta agir de forma a desvelar novos sentidos.

Cardinalli (2000) afirma que a daseinsanalyse, fundamentando-se na fenomenologia, tem o papel de "priorizar o entendimento do paciente a partir dele mesmo na maneira como ele vive" (p. 12). Em outro trabalho (2005) concebe que o objeto de intervenção da psicoterapia não é a doença, mas sim o paciente com o seu próprio existir. Assim "o foco do trabalho psicoterápico é favorecer a aproximação e a compreensão do paciente da sua própria experiência” (2005, p. 59). A experiência é uma totalidade de relações significativas que constituem o mundo do ser. A autora afirma que o ponto de partida da terapia é a maneira como o paciente é naquela situação; seja imaturo, seja dependente, o inicio da terapia se dá a partir do modo de ser do paciente; assim, em certos casos, o primeiro objetivo terapêutico é elaborar um contexto onde o paciente se aceite e admita tal como é, apropriando-se de seus sofrimentos e limitações. 


\section{Postura do psicoterapeuta}

David Cytrynowicz (1978/1997), em conformidade com o existencial "abertura", propõe que o psicoterapeuta deve "auxiliar o paciente a desvelar suas próprias possibilidades e fortalecê-lo com o resguardo que lhe dê a suficiente segurança, confiança e coragem para assumir o risco e as incertezas inerentes à sua condição de ser-aberto" (p. 67). O terapeuta, ainda segundo o autor, age como um jardineiro, determinando as condições adequadas para o desabrochar da riqueza humana, ou seja, o desvelamento do poder-ser do paciente. Assim a daseinsanalyse abre ao paciente seu próprio existir, seu horizonte de possibilidades. Porém cabe ao paciente a tarefa de cuidar da sua própria existência, realizar as escolhas de forma responsável, sendo o terapeuta incumbido de lembrar o paciente de que ele é guardião do próprio destino.

Pompéia (1978/1997) pontua que o terapeuta deve abordar a vivência pessoal do paciente, ou seja, sua experiência, uma vez que o psicoterapeuta se presta a "compreender o problema que se apresentava de fato" (p. 72). Esse abordar a vivência pode ser melhor feito através da descrição das experiências do paciente; Cardinalli (2000) afirma que o terapeuta deve solicitar "que o próprio paciente perceba o que e como está vivendo” (p. 13), essa descrição da experiência favorece a aproximação do paciente de si mesmo e do seu modo de viver. Maria Cytrynowicz (1997) aponta que o terapeuta deve acompanhar com disponibilidade a procura empreendida pelo paciente na busca de uma saída para as restrições enfrentadas na sua vida. Para tanto o terapeuta deve ser capaz de experienciar um mundo comum com ele, um mundo constituído por uma totalidade referências do futuro longínquo ou mesmo do passado remoto, todos presentificados na fala do paciente. Além disso, segundo a autora, o terapeuta deve aceitar o paciente e as suas diferenças e particularidades manifestadas em seu mundo de referências. Além de oferecer um ambiente acolhedor, manejar o silêncio e a espera, saber lidar com o recolhimento, o terapeuta deve, segundo a autora, não esquecer as gargalhadas, que favorecem a intimidade. Destacamos que o terapeuta deve acompanhar o paciente no seu processo, experienciar o seu mundo com ele e aceitar o paciente nas suas manifestações.

O texto de Cardinalli (2000) traz diversas contribuições em torno da proposta da psicoterapia daseinsanalítica, da postura do terapeuta e procedimentos terapêuticos nessa perspectiva. O terapeuta, segundo a autora, deve atentar-se ao modo como o paciente lida ou se ocupa em relação àquilo com o que vive e traz no ambiente clínico. O terapeuta deve compreender o paciente a partir do próprio existir do paciente. Na sua relação com o paciente, 0 terapeuta deve olhar ao paciente em sua concretude existencial. Em seguida a autora cita Spanoudis (1978/1997) para postular que o terapeuta deve "clarear e tornar compreensível para o paciente 'como ele se relaciona com tudo o que encontra, como se comunica com o próximo, como está afinado (disposto) em relação a tudo que vivencia”" (p. 13). Assim a postulação de Cardinalli, fundamentada em Spanoudis, sustenta que o terapeuta deve acompanhar o paciente no processo de elucidar as suas escolhas e referências em modo de ser. Sipahi e Vianna (2002) apresentam posição similar nas suas considerações em torno da psicoterapia com pessoas com dependência. Os autores afirmam que o terapeuta deve "buscar a compreensão de como a pessoa vivencia o acontecimento de estar no mundo, atentando para como se apresenta sua dependência” (p. 91).

Cardinalli (2000) afirma que o terapeuta, ao compreender o paciente a partir de seu próprio existir, fomenta no paciente a percepção de o que e como está vivendo. Assim ele aproxima-se de si mesmo e de seu modo de viver, podendo viver a situação terapêutica de forma autêntica. Para isso, a autora cita, o terapeuta deve dispor a situação terapêutica de tal forma que o paciente se sinta aceito. A partir dessa vivência de aceitação e a possibilidade oferecida pelo contexto clínico de compreender-se, ocorre a mudança terapêutica. A autora também salienta a necessidade do terapeuta de estar disponível ao cliente, uma vez que existe a busca pela mudança na terapia, porém a mudança gera temor. Em outro trabalho (2005) a autora também destaca a necessidade do terapeuta aceitar o paciente inteiramente, com todas as suas belezas e feiuras. Em suma, Maria Cytrynowicz e Cardinalli estabelecem em comum, como atribuições do terapeuta, acompanhar o paciente em seu modo de ser, aceita-lo em suas manifestações, e experienciar com ele seu mundo de referências.

Vianna, Hermann, Puzzilli, Kuroda e Maria Cytrynowicz publicaram em 2001 cinco artigos agrupados em um eixo comum de psicoterapia com crianças institucionalizadas. Esses textos são frutos de uma palestra proferida na Associação Brasileira de Daseinsanalyse em 2000. Pompéia (2004) afirma que o terapeuta tem como tarefa aproximar-se do paciente, posição em conformidade com Vianna (2001), que estabelece que o terapeuta deve elaborar uma relação de proximidade com o paciente e além disso olhar à individualidade deste e acompanha-lo. Vianna (2001) afirma que a psicoterapia "tem um olhar voltado para sua [do paciente] individualidade, cuidando de suas necessidades mais particulares" (p. 93). Outro texto que abordou a individualidade ou singularidade do paciente em terapia foi o de Freitas (2011). O olhar atento à individualidade é uma medida de compreensão da existência do paciente a partir dela própria, tal como destacado por Cardinalli (2000). Nesse ponto enfatizamos a relevância do conceito das Man tal como abordado por Heidegger (1927/2012), uma vez que, como aponta Cerbone (2014), o Dasein cotidiano está sob o jugo do das Man (a-gente), uma autoridade anônima, que faz o homem alinhar-se aos outros. Embora em um grupo o homem seja um indivíduo entre os vários indivíduos no sentido numérico, há uma perda da individualidade uma vez que a autodeterminação se limitou devido ao deixar-se levar pelo normativo 
do das Man. De acordo com Pompéia (2004), o Dasein, ao enfrentar angústia, busca abrigo; o das Man promove esse abrigo, conforto e libertação do Dasein da indeterminação assustadora que deve enfrentar.

Hermann (2001) caracteriza o processo terapêutico como um processo vivencial e emocional, divergindo, dessa forma, de uma concepção pedagógica de psicoterapia. $\mathrm{O}$ autor afirma que o brincar "sustenta e revela o modo particular da criança diante do terapeuta, pois a experiência viva do brincar introduz, para a criança, um leque de novas possibilidades" (p. 97). Em seu relato há tanto a proposição de brincadeiras quanto o próprio brincar com a criança. Por outro lado, pontua que o terapeuta deve possuir um olhar psicoterapêutico, ou seja, se abster de julgamentos morais. Cardinalli (2005) afirma que "todas as possibilidades do paciente devem ter uma chance de emergir e não devem considerar as ideias, desejos ou julgamentos pessoais do analista” (p. 61), assim o terapeuta deve cuidar do paciente sem interferir a partir das suas próprias referências e sentidos.

Puzzilli (2001) lista as queixas iniciais em seu estudo de caso e pontua que o terapeuta deve conhecer o paciente em sua real condição, em detrimento de conhece-lo a partir da perspectiva de quem traz a queixa da criança. Relata que como psicoterapeuta se esforçava para aproximar-se do paciente e suas dificuldades e acompanha-lo durante a psicoterapia, tal como postulado por Cardinalli (2000), Maria Cytrynowicz (1997) e Vianna (2001). No texto de Kuroda (2001) também percebemos a presença do acompanhamento e da proximidade através do desenho. $\mathrm{O}$ autor relata que paciente e terapeuta realizavam seus próprios desenhos e a partir disso eram compartilhadas ideias, olhares e opiniões, ou seja, eram realizadas descobertas. Freitas (2011) afirma que "o terapeuta deve acompanhar a experiência originária de errância de seu paciente e tornar-se testemunha das possibilidades de significado descobertas através desta jornada" (p. 80). Também Saffi (2002, p. 99-100) traz um estudo de caso onde relata diversas passagens demonstrando a atitude básica do terapeuta de acompanhar o cliente. Esse acompanhamento se demonstra pela receptividade ao modo de ser do paciente por parte da terapeuta, bem como a busca por uma aproximação terapêutica. Outro texto em que 0 acompanhamento está presente é o de Sipahi e Vianna (2002) onde os autores defendem que

no estabelecimento da relação terapêutica o terapeuta deve colocar-se a serviço do outro, oferecendo-se como companhia, [...] [aproximando-se] de seus sofrimentos, cuidando de acolher seus medos, incertezas, vergonhas, com uma escuta e um olhar que lhe permitam aproximar-se de si mesmo. Neste encontro, a escuta e o olhar terapêuticos revelam as possibilidades que lhe estão veladas, mas que se fazem presentes e permitem acesso a novos modos possíveis de ser no mundo. (p. 90)
Concebemos que a escuta e olhar terapêuticos que permitem acesso a esses novos modos possíveis de ser e que norteiam as atitudes gerais do terapeuta foram explicitadas por Maria Cytrynowicz (1997). Acompanhar o paciente no seu processo permite experienciar o seu mundo com ele e aceitar o paciente nas suas manifestações. Na verdade, esse acompanhamento só pode ser feito através da aceitação, por parte do terapeuta, das manifestações do paciente, ou seja, do modo de ser do paciente.

Pompéia (2004) afirma que o trabalho do terapeuta é acolher tudo que vem ao encontro na situação terapêutica. O autor aproxima acolhimento com receptividade, ou seja, um comprometimento com aquilo que está sendo acolhido no sentido de aceitar a manifestação como fazendo parte de um processo. Sendo parte de um processo a manifestação não é a condição final, mas sim o meio, que está em constante desenvoltura. $\mathrm{O}$ autor afirma que "aceitar é fundamentalmente um aproximar. E além de aceitar é importante também poder acolher o que acontece. A diferença sutil entre aceitar e acolher talvez seja esta: acolher supõe um movimento" (p. 17).

Maria Cytrynowicz (2001) comenta os estudos de caso de Vianna, Hermann, Puzzilli e Kuroda e pontua que o terapeuta atua no sentido de libertar a criança para as verdadeiras possibilidades de seu existir. $\mathrm{O}$ requisito fundamental para tal ação é evitar isolar a criança numa história com passado e futuro já demarcados. A tarefa do terapeuta, desse modo, é buscar as origens, em seguida a autora esclarece afirmando que "a busca de origem quer dizer buscar o sentido original, o modo próprio, o que é mais próximo, encontrar a familiaridade com a própria vida, história pessoal e particular" (p. 122).

Pompéia (2002), abordando a psicoterapia com psicóticos, pontua a necessidade do terapeuta suspender seus julgamentos acerca da veracidade da experiência do paciente em seu contraste com a fatualidade daquilo que vive. Assim cita o exemplo de um paciente que em delírio pode afirmar estar sendo perseguido pela CIA; a perseguição sendo realizada de fato ou não, não importa ao terapeuta, mas a experiência de estar sendo perseguido é trabalhada pelo terapeuta.

Pompéia (2002) destaca que "a referência para o psicoterapeuta é o sentido da vida, é o significado" (p. 55), uma vez que o autor defende a relevância que os homens depositam no sentido das coisas. O autor pontua que eventualmente um psicoterapeuta atuando junto a um paciente terminal deve auxiliar na busca pela preservação do sentido até o fim; atuando junto a um paciente psicótico o psicólogo, ou seja, psicoterapeuta, deve "reintroduzir na história do paciente a experiência tão intensa que ele viveu no surto; é torna-la parte da vida dele e não um pedaço a ser jogado fora; é trazer o significado da experiência psicótica para junto da vida normal” dessa forma é possível "que ele veja como as emoções vividas no surto tinham e continuam a ter sentido na totalidade de sua história” (p. 70). A partir dessa recuperação da estrutura 
do sentido o paciente pode investir novamente nas suas relações e no seu projeto. A partir de Sipahi e Viana (2002) destacamos que o terapeuta deve atuar de forma a preservar o sentido da experiência humana, assim novas significações desdobram-se e torna-se possível novos modos de ser. Cardinalli (2005) afirma que o papel do terapeuta é buscar o desvelamento do sentido da experiência do paciente e esclarecer o horizonte no qual ele está vivendo. Em seguida, fundamentando-se em Boss, a autora afirma que a tarefa do terapeuta "é ajudar os pacientes a se desenvolverem no sentido das próprias possibilidades de sua existência” (p. 60).

Percebemos que o termo sentido é usado diversas vezes pelos diferentes autores citados, salientando a relevância dessa questão na prática psicoterápica daseinsanalítica. A partir do pensamento de Heidegger (1927/2012), especialmente no §32 de "Ser e Tempo" "sentido é aquilo em que a compreensibilidade de algo se mantém”, assim algo só é compreendido como algo a partir do sentido. O sentido é relevante na prática psicoterápica na medida em que ele desvela as relações que o paciente tem com o mundo e como ele as sustenta e é por elas sustentado (Jardim, 2013).

Sipahi e Vianna (2002) colocam ênfase na ressignificação do tempo no trabalho com pessoas com dependência. Afirmam que o terapeuta deve ser capaz de propiciar ao paciente o acesso ao seu futuro como um poder-ser, ou seja, é preciso trabalhar promovendo uma nova forma de relacionamento com o futuro. Nesse sentido o próprio setting deve ser disposto de forma a colaborar com a assimilação da temporalidade de uma outra forma pelo paciente. Por outro lado citam como papel do terapeuta "auxiliar o cliente na construção de uma história mais propriamente sua, mesmo com as incertezas do futuro" (p. 92). Esse processo de construção de sua própria história, alertam os autores, envolve riscos, medos e abandonos, tal como o incômodo da solidão que a liberdade em se construir provoca, tal como expressa Sartre citado por Pompéia (2000).

Cardinalli (2005) aponta, fundamentando-se em Boss, que a prática psicoterápica deve evitar modos interventivos de atuação, ou seja, o terapeuta deve evitar ocupar-se daquilo que deve ser feito pelo próprio paciente: as escolhas que conduzem sua existência. Assim o terapeuta deve oferecer um cuidado antecipativo.

\section{Interpretação integradora: panorama da daseinsa- nalyse no Brasil}

Percebemos uma dispersão entre as diversas concepções de objetivos da psicoterapia e das posturas do terapeuta, e em nossa interpretação tal dispersão é engendrada a partir de uma orientação única da daseinsanalyse: o cuidado do próprio ser do paciente. Dessa forma a daseinsanalyse pode ser considerada uma terapia na compreensão primordial do termo.
Holanda (2011) tematiza o cuidado nas modalidades médica e psicológica e assim aponta a diferenciação entre o cuidado psiquiátrico e a psicoterapia. Herdados da Grécia antiga, os conceitos de iatriké, cuidar do próprio corpo, opõe-se à therapeia, cuidar do próprio ser, e fundamentam ambas as modalidades de cuidado: o cuidado psiquiátrico e a psicoterapia. O terapeuta oferece um cuidado mediado pela palavra, que interpreta e desvela sentidos; a "cura" promovida por ele é mais do que a remissão de sintomas, mas sim uma via de cuidar do próprio ser e promoção do cuidado de si. Servindo-se da fala o terapeuta, na modalidade psicoterapia, cuida do corpo e da alma através da alma, ou seja, através da própria manifestação daquele que está sendo cuidado. Por outro lado, como uma expressão da iatriké, o cuidado psiquiátrico oferece um cuidado do corpo e da alma através do corpo, ou seja, via medicações.

Psicoterapia, portanto, é um cuidado do corpo e da alma através da alma, sendo esta a mediadora desse cuidado. Em outras palavras, a psicoterapia cuida do próprio ser através do compartilhamento entre terapeuta e paciente. Dessa forma, uma nova compreensão ou desvelamento dos sentidos em que se fundamenta a existência, promoção da liberdade existencial com acesso a novas possibilidades de ser e a promoção da resolutividade na condução da própria existência se apresentam como os eixos essenciais dos objetivos apresentados pelos diferentes autores. E todos eles apontam ao cuidado de si, a promoção do cuidado de si. O desenvolvimento do ser, que promove o cuidado de si, é o polo onde convergem todos os esforços do terapeuta.

Maria Cytrynowicz (1997) e Cardinalli (2005) concebem que a relação paciente-terapeuta compõe o cerne do processo psicoterápico, já que este ocorre graças a um espaço comum entre essas duas figuras trabalhando no sentido de promover mudanças na vida do paciente. Tais mudanças se expressam através de uma nova compreensão de sua vida, que se amplia; ou através de novos modos de ser, que são desvelados, porém cabe ao paciente a condução da própria vida. Portanto em todo processo de cuidado o terapeuta acompanha o paciente no seu empreendimento; isso implica a necessidade de um olhar clínico próprio à psicoterapia; a necessidade de aceitar o paciente nos seus modos de ser; esclarecer a tonalidade afetiva que ilumina a clareira do ser e tempera a experiência; aproximar-se do paciente e sua experiência, compartilhando com o paciente.

Conforme Pompéia (2014), fundamentando-se no pensamento heideggeriano, o ente humano difere-se de qualquer outro ente pela sua capacidade de sonhar, colocar-se adiante, projetar-se no futuro. Assim ele afirma que "a existência se situa na abertura do que ainda não é” (p. 18), ou seja, na possibilidade de ser. Esse poder-ser é o que distingue o homem de qualquer outro ente. Herdada de Husserl, e sua crítica da apropriação realizada pela ciência naturalista da subjetividade humana, 
Heidegger desenvolve um novo olhar à experiência humana e justamente esse olhar fundamenta a prática terapêutica daseinsanalítica.

Pompéia (1978/1997a) afirma que ao longo do processo psicoterapêutico há a possibilidade do paciente enfrentar sensações de desconforto ou mal estar e que isso se deve ao fato de que na psicoterapia revolve-se antes de se resolver. Porém o autor destaca que sua concepção de resolução é diferente de uma resolução de problemas como um concerto mecânico; está mais próxima da concepção de resolução como um modo de ser, ou seja, a clareza de propósito e firmeza que o paciente desenvolve na psicoterapia. Dessa forma justifica-se a necessidade do terapeuta acompanhar o paciente no seu processo, tal como citado por diversos autores (Puzzilli, 2001; Cardinalli, 2000; Maria Cytrynowicz, 1997; Vianna, 2001; Kuroda, 2001; Freitas, 2011; Saffi, 2002 e Sipahi \& Vianna, 2002) e agir tal como um jardineiro, como expresso por David Cytrynowicz (1978/1997), oferecendo as condições para o paciente desenvolver o cuidado de si. Por outro lado, Pompéia (2000) afirma que a psicoterapia se desenvolve via linguagem poética e que o terapeuta, ao compreender o paciente, é tocado por este, assim o autor fornece subsídios para a compreensão de como o terapeuta deve acompanhar o paciente, quais são os subsídios para esse acompanhamento.

Outra questão presente nos textos e que chamou nossa atenção foi a realização de estudos etimológicos. David Cytrynowicz (1978/1997) discute a questão da abertura do ser na compreensão da psicoterapia e propõe que "as palavras, mesmo as aparentemente óbvias, não podem ser tomadas como autoevidentes se estivermos seriamente empenhados numa compreensão mais primordial do que falamos" (p. 64). Spanoudis (1976/1997) em esforço similar realiza um breve estudo do termo tédio. O autor se justifica dizendo: "insistimos nas definições e etimologia da palavra não por razões escolásticas, mas [para] captar tanto o quanto é possível o que ela nos revela, nos comunica” (p. 50). Heidegger (1975/2012) também realiza estudos etimológicos, apontando que buscar a origem dos termos essentia e existentia elucida o horizonte de compreensão e interpretação daquilo indicado pelos dois conceitos (§11). Assim o exercício etimológico é fundamental no desvelamento de sentidos dos termos usados no nosso cotidiano. Encontramos estudos etimológicos em Maria Cytrynowicz (2001) e Pompéia (2000) e outros autores.

Enfatizamos a relevância da realização dos estudos etimológicos para o desvelamento do sentido primordial das palavras que empregamos, especialmente os terapeutas e estudiosos da existência humana. Esse desvelamento permite uma apropriação genuína da experiência designada pelo termo, assim será possível distinguir a emoção do sentimento, que não raro são enclausurados em um leito de Procusto que restringe ou amplia indevidamente a manifestação desses dois estados de ânimo tratados como se fossem uma mesma modulação de afeto. Assim será possível distinguir ouvir, como a mera percepção dos sons, de escutar, um exercício de ouvir com atenção, desvelando sentidos e mantendo-se junto àquele que fala. Assim será possível resgatar a própria direção e sentido de terapia, o cuidado do próprio ser.

\section{Novos contextos de atuação}

Pompéia (2000) ao definir terapia como "a procura, via poiesis, pela verdade que liberta para a dedicação ao sentido" (p. 29), abre um leque de possibilidades de atuação em outros contextos, marcadas essencialmente pelo favorecimento do cuidado da própria existência. Esse cuidado, compreendido como manejo, ou lida, dá ao ser a condição de agente na construção de si próprio, em detrimento de posições geradoras de passividade ou privação existencial. Assim, terapia, como um cuidado do próprio ser, ao invés de se restringir ao contexto do consultório individual se abre a novas formas de cuidado.

David Cytrynowicz (1978/1997) estabelece a postura do psicoterapeuta como a de auxiliar o paciente no processo de desvelamento de suas possibilidades. Concebemos que tal auxílio, ou seja, promover as condições para que o paciente desvele suas possibilidades, também pode estender-se a outros contextos. Combinando o oferecimento de um cuidado antecipativo, tal como abordado por Cardinalli (2005) e a postura de aceitação e acolhimento por parte do terapeuta, tematizada por Maria Cytrynowicz (1997) e Pompéia (2004), propomos que a daseinsanalyse pode ser fundamento para a prática de redução de danos. A redução de danos enfatiza a criação de um espaço onde a própria pessoa alvo da redução de danos seja prioridade no estabelecimento de programas ou metas de tratamento, e o redutor é quem cria esse espaço. O redutor, orientado pela perspectiva daseinsanalítica, ao favorecer esse espaço promove as condições para o desvelamento de possibilidades existenciais da pessoa alvo da redução de danos (Marlatt, 1999).

A perspectiva daseinsanalítica também é coerente com a aceitação e empatia da redução de danos. Ao experienciar o mundo com o paciente, tal como destacado por Maria Cytrynowicz (1997) o terapeuta pode agir tal como um redutor, oferecendo um cuidado singular e humanizado à pessoa alvo da redução de danos. Além disso, é importante evitar julgamentos morais, tal como foi tematizado por Hermann (2001) e Cardinalli (2005), tanto como uma forma de estabelecimento de vínculo, quanto como caminho para o cuidado antecipativo visado pela daseinsanalyse; tal cuidado é promotor do desvelamento das possibilidades e consequente alteração do modo de ser por parte da pessoa alvo da redução de danos.

Cardinalli (2011) apresenta as contribuições da fenomenologia existencial para a atuação do psicólogo em contextos amplos, fundamentando-se no entendimento da daseinsanalyse de saúde e doença. A autora afirma 
que o entendimento daseinsanalítico dessa questão baseia-se no poder-ser e na liberdade do homem, assim as experiências humanas são situadas em uma totalidade existencial específica.

Nossa intenção, longe de visar patologizar o fenômeno do uso ou abuso de drogas, é maneja-lo a partir da experiência de restrição expressa pela própria pessoa alvo da redução de danos na relação com o redutor. Assim, nessa perspectiva centrada no cuidado a partir da demanda levantada pela pessoa, a existência e o horizonte de possibilidades da pessoa alvo compõem o cerne do estabelecimento de demandas e do oferecimento de cuidado.

Sipahi e Vianna (2002) realizaram um estudo teórico onde abordaram o fenômeno da dependência de drogas a partir da fenomenologia existencial e traçaram alguns apontamentos acerca do processo terapêutico de uma pessoa com dependência. Os autores destacam a angustia frente ao futuro indeterminado como um motivador para o uso de drogas, posição em conformidade com Boss (1981, p. 17); consideramos relevante levar em conta a tematização da angustia existencial realizada por Pompéia (2004). Sipahi e Vianna (2002) destacam que o uso de drogas, devido ao prazer imediato, promove uma ressignificação da relação do homem com o tempo, uma vez que o ser experimenta um alívio da necessidade de cuidar do seu futuro. Por outro lado, os autores afirmam que outras fontes de prazer são negligenciadas, assim verifica-se a restrição em suas existências. Destacamos algumas propostas para a psicoterapia nesse contexto apresentadas pelos autores, tais como o desvelamento de sentidos, que favorece novos modos de ser. Em contraponto à abstinência como única via, os autores propõem a busca por liberdade, garantindo ao homem a possibilidade de realizar seu poder-ser. $\mathrm{O}$ terapeuta deve acolher, aproximar-se e acompanhar a partir da escuta e olhar terapêuticos. Finalmente estabelecem a necessidade de proporcionar uma forma diferente de relacionar-se com o futuro, ampliando as possibilidades no horizonte do ser. Concebemos que esse trabalho pode ser considerado um fundamento para a prática de redução de danos devido às suas contribuições na compreensão do fenômeno da dependência a partir da existência humana, bem como a terapêutica proposta, que cuida do próprio ser do usuário, a partir as próprias escolhas do usuário. Em consonância com os princípios da Saúde Coletiva e com a fundamentação daseinsanalítica é possível desenvolver uma perspectiva em redução de danos que aborde o existir humano em sua factualidade.

\section{Considerações finais}

Concebemos que são necessárias maiores definições operacionais na produção brasileira em daseinsanalyse, especialmente acerca das atitudes e posicionamentos do terapeuta. As definições operacionais favorecem a comunicação e divulgação científica, pois estabelecem um sentido comum a conceitos com várias interpretações e entendimentos.

Nesse estudo não foram destacadas as concepções de psicoterapia e não foram apontadas as concepções de psicopatologia, que são fundamentais para a elaboração de um panorama mais elaborado da psicoterapia daseinsanalítica no Brasil. Além disso, em vistas a um panorama mais elaborado, é preciso estender o processo de busca por artigos a todos os periódicos disponíveis.

A daseinsanalyse enquanto prática psicoterápica não possui, propriamente dito, um modelo de homem; fechado, encapsulado, olhado e abordado indiretamente através de construtos metapsicológicos. A daseinsanalyse se funda em uma concepção de ser cuja essência é a existência; o cuidado oferecido pelo terapeuta, dessa forma, é um cuidado do próprio ser, sendo a daseinsanalyse uma therapeia no sentido grego antigo. A atribuição de acompanhar o paciente, postulada por diversos autores, é justificada pela proposta de cuidar do próprio ser da therapeia. Em outra ocasião defenderemos a tese de que todo cuidado psicológico é uma prática de therapeia. No momento satisfazemo-nos em concluir: a daseinsanalyse, em detrimento de posições metapsicológicas ou encapsulantes do ser humano, cuida do próprio ser da pessoa que se apresenta em toda sua expressão existencial.

\section{Referências}

Associação Brasileira de Daseinsanalyse. (2015). Histórico. Acesso em 25 de Dezembro de 2015, disponível em Site da Associação Brasileira de Daseinsanalyse: http://www.daseinsanalyse.org/page.php?id=17.

Boss, M. (1963). Psychoanalysis and Daseinsanalysis. New York: Basic Books.

Boss, M. (1981). Angústia, Culpa e Libertação Psicoterápica. São Paulo: Duas Cidades.

Boss, M. \& Condrau, G. (1976/1997). Análise ExistencialDaseinsanalyse. Daseinsanalyse - Revista da Associação Brasileira de Daseinsanalyse (1, 2 e 4), p. 23-35.

Cardinalli, I. E. (2000). Daseinsanalyse e Psicoterapia. Daseinsanalyse - Revista da Associação Brasileira de Daseinsanalyse, 9, 11-18.

Cardinalli, I. E. (2011). A Saúde e a Doença Mental Segundo a Fenomenologia Existencial. Daseinsanalyse - Revista da Associação Brasileira de Daseinsanalyse, 15 e 16, 98-114.

Correia, E., Correia, K., Cooper, M. \& Berdondini, L. (2014). Psicoterapia existencial latinoamericana em la actualidad. Revista Latinoamericana de Psicoterapia Exstencial, 9(5), 26-37.

Cytrynowicz, D. (1997). Psicoterapia: uma aproximação daseinsanalítica. Daseinsanalyse - Revista da Associação Brasileira de Daseinsanalyse. 1, 2 e 4. 63-70 (Original publicado em 1978). 
Cytrynowicz, M. B. (1997). Relação Analista-Analisando: uma abordagem daseinsanalítica. Daseinsanalyse - Revista da Associação Brasileira de Daseinsanalyse, 8, 30-38.

Cytrynowicz, M. B. (2001). Comentários. Daseinsanalyse - Revista da Associação Brasileira de Daseinsanalyse, 11, 116-125.

Cardinalli, I. E. (2000). Daseinsanalyse e Psicoterapia. Daseinsanalyse - Revista da Associação Brasileira de Daseinsanalyse, 9, 11-18.

Cardinalli, I. E. (2005). A Contribuição das Noções de Ser-noMundo e Temporalidade Para a Psicoterapia Daseinsanalítica. Daseinsanalyse - Revista da Associação Brasileira de Daseinsanalyse, 14, 55-63.

Cardinalli, I. E. (2012). Daseinsanalyse e Esquizofrenia: Um estudo na obra de Medard Boss. São Paulo: Escuta.

Cerbone, D. (2014). Fenomenologia. Rio de Janeiro: Editora Vozes.

Evangelista, P. E. (2013). A Daseinsanalyse de Medard Boss. Em: P. E. Evangelista (Org.), Psicologia FenomenológicoExistencial: Possibilidades da atitude clínica fenomenológica (p. 139-157). Rio de Janeiro: Via Verita.

Freitas, D. P. (2011). Daseinsanalyse e Liberdade. Daseinsanalyse - Revista da Associação Brasileira de Daseinsanalyse, 15 e 16, 56-84.

Gendlin, E. T. (1978/79). Befindlichkeit: Heidegger and the philosophy of psychology. Review of Existential Psychology and Psychiatry, 16(1-3), 43-71. Recuperado em: 07/03/2016 de: http://www.focusing.org/gendlin/docs/gol_2147.html.

Giovanetti, J. P. (2012). Psicoterapia Fenomenológico-Existencial: Fundamentos filosóficos-antropológicos. Belo Horizonte: FEAD.

Heidegger, M. (1927/2012). Ser e Tempo. (F. Castilho, Trad.) Campinas: Editora da UNICAMP: Rio de Janeiro: Vozes.

Heidegger, M. (1975/2012). Os Problemas Fundamentais da Fenomenologia. (M. A. Casanova, Trad.) Rio de Janeiro: Editora Vozes.

Heidegger, M. (1987/2001). Seminários de Zollikon. São Paulo: EDUC: Petrópolis: Vozes.

Hermann, M. C. (2001). Relato de um Processo Terapêutico de uma Criança Institucionalizada. Daseinsanalyse, 10, 94-102.

Holanda, A. F. (2011). Fenomenologia do "Cuidado": reflexões para um olhar sobre o binômio saúde-doença. Em: A. J. Peixoto \& A. F. Holanda, Fenomenologia do Cuidado e do Cuidar: perspectivas multidisciplinares (67-83). Curitiba: Juruá

Holanda, A. F. (2014). Fenomenologia e Humanismo: Reflexões necessárias. Curitiba: Juruá.

Kuroda, S. (2001). Descoberta de um Encontro Através do Brincar. Daseinsanalyse - Revista da Associação Brasileira de Daseinsanalyse, 10, 112-115.

Jardim, L. E. (2013). Ação e Compreensão na Clínica Fenomenológica Existencial. Em: P. E. Evangelista (org), Psicologia Fenomenológico-existencial: possibilidades da atitude clínica fenomenológica (p. 45-74). Rio de Janeiro: Via Verita.
Marlatt, A. (1999). Redução de Danos: estratégias práticas para lidar com comportamentos de alto risco. Porto Alegre: Artmed.

Mondin, B. (2014). Curso de Filosofia: Os filósofos do ocidente (Vol. 3 Coleção Filosofia). São Paulo: Paulus.

Pompéia, J. A. (1997). Psicoterapia e Verdade. Daseinsanalyse - Revista da Associação Brasileira de Daseinsanalyse, 1, 2 e 4, 71-76 (Original publicado em 1978).

Pompéia, J. A. (2000). Uma Caracterização da Psicoterapia. Daseinsanalyse - Revista da Associação Brasileira de Daseinsanalyse, 9, 19-30.

Pompéia, J. A. (2002). Psicose e Psicoterapia. Daseinsanalyse - Revista da Associação Brasileira de Daseinsanalyse, 11, 52-71.

Pompéia, J. A. (2004). Aspectos Emocionais na Terapia Daseinsanalítica. Daseinsanalyse - Revista da Associação Brasileira de Daseinsanalyse, 13, 5-20.

Pompéia, J. A. \& Sapienza, B. T (2014). Na Presença do Sentido: uma aproximação fenomenológica a questões existenciais básicas. São Paulo: EDUC; ABD.

Prado, M. F. (2001). Uma Apresentação Sobre os Seminários de Zollikon. Daseinsanalyse - Revista da Associação Brasileira de Daseinsanalyse, 11, 29-48.

Puzzilli, A. (2001). Uma História de Abandono. Daseinsanalyse - Revista da Associação Brasileira de Daseinsanalyse, 11, 103-111.

Saffi, F. (2002). História de Camila. Daseinsanalyse - Revista da Associação Brasileira de Daseinsanalyse, 11, 93-105.

Sipahi, F. M. \& Vianna, F. C. (2002). A Dependência de Drogas e a Fenomenologia Existencial. Daseinsanalyse - Revista da Associação Brasileira de Daseinsanalyse, 11, 85-92.

Spanoudis, S. (1997). Neurose do Tédio. Daseinsanalyse - Revista da Associação Brasileira de Daseinsanalyse. 1, 2 e 4, 50-53 (Original publicado em 1976).

Torraco, R. J. (2005).Writing Integrative Literature Reviews: guidelines and examples. Human Resource Development Review, 4(3), 356-367.

Vianna, F. C. (2001). A História de Julia. Daseinsanalyse - Revista da Associação Brasileira de Daseinsanalyse, 10, 103-111.

Breno Augusto da Costa - Psicólogo pela Universidade Federal do Triângulo Mineiro (UFTM). Membro-fundador da Liga Acadêmica de Fenomenologia Existencial (LAFEN/UFTM). Redutor de Danos pela Escola de Redução de Danos de Uberaba. Email: brenobac@gmail.com

Recebido em 15.03.2016 Aceito em 10.09.2016 